Bangladesh Journal of Bioethics 2010; 1(3):15-21

\title{
ETHICAL ISSUES IN PUBLIC HEALTH RESEARCH
}

\author{
Abu Sadat Mohammad Nurunnabi ${ }^{1}$, Mahmood-uz-jahan ${ }^{2}$, Shaorin Tanira $^{3}$ \\ 1. Dr. Abu Sadat Mohammad Nurunnabi, Lecturer, Department of Anatomy, Dhaka Medical College, \\ Dhaka. Email: shekhor19@yahoo.com. (Corresponding author) \\ 2. Dr. Mahmood-uz-jahan, Deputy Director, Bangladesh Medical Research Council (BMRC), Dhaka. \\ 3. Dr. Shaorin Tanira, Coordinator (Health), MCH-FP Clinic, Manabik Shahajya Sangstha (MSS), Dhaka.
}

\begin{abstract}
Public health is the societal approach to protecting and promoting health. Public health ethics can be defined as the identification, analysis, and resolution of ethical problems arising in public health practice and research. The emerging interest in ethical issues in public health research and practice reflects both the important societal role of public health and the growing public interest in the scientific integrity of health information and the equitable distribution of health care resources. This article provides an overview of ethical issues in public health research for young researchers and readers who do not necessarily have an in-depth knowledge of public health ethics. A framework of ethics analysis geared specifically for public health is needed to provide practical guidance for public health professionals and researchers in Bangladesh. Bangladesh Medical Research Council is playing a role in setting a standard in the field of biomedical research including public health concerning its strategy and ethical issues and by helping different health institutes to build up a research environment. Though public policy is based on many factors in addition to public health goals and ethical reasoning, it should not lead to the politically preferable option for a given time.
\end{abstract}

Key words: Public health, Public health research, Ethical issues, National Health Research Strategy, Bangladesh Medical Research Council.

Introduction: In 1923, the great public health scholar C.S. Winslow stated that public health is "the science and art of preventing disease, prolonging life, and promoting physical health and efficiency through organized community efforts"1. Public health is the societal approach to protecting and promoting health. Generally through social, rather than individual, actions, public health seeks to improve the well-being of communities ${ }^{2}$. Public health activities include community collaborations and partnerships for health and the identification of priorities for public health action. Recent articles have included conceptual frameworks of public health ethics and overviews of historical developments in the field ${ }^{3,4}$. The emerging interest in ethical issues in public health research and practice reflects both the important societal role of public health and the growing public interest in the scientific integrity of health information and the equitable distribution of health care resources. Attention to ethical issues can facilitate the effective planning, implementation, and growth of a variety of public health programs and research activities ${ }^{5}$. Public health 
ethics, which can be defined as the identification, analysis, and resolution of ethical problems arising in public health practice and research, has different domains from those of medical ethics. Ethical concerns in public health often relate to the dual obligations of public health professionals to acquire and apply scientific knowledge aimed at restoring and protecting the public's health while respecting individual autonomy ${ }^{6}$. Amartya Sen, a Nobel winner economist, emphasizes the importance of health to justice by saying that "health is among the most important conditions of human life and critically significant constituent of human capabilities which we have reason to value"7.

Public health professionals must go through the steps of an ethics analysis to assure the public of their integrity. The public must feel confident that public health professionals will offer only those proposals that will improve the health of the public, that proposed measures are minimally burdensome, and that a fair procedure has determined that the magnitude of the problem and the ensuing benefits justify overriding conflicting moral claims ${ }^{8}$. Ideally, the government would set a public health policy which include research strategies, ethical concerns, priority of public demand, cost-benefit ratio and, of course, "by reference to scientific or objective knowledge, maximizing the value of health and well-being within the population".

Moral Reasoning In Public Health: Moral reasoning involves ethical questions and reaching a decision with the help of judgment and rational analysis. Among different methods of moral reasoning, the following two are considered to be more pronounced ${ }^{5}$.

\section{Princple-based approach:}

The principles of beneficence, nonmaleficence, autonomy, and justice, as explained by Beauchamp and Childress ${ }^{10}$, seek to reduce morality to its basic elements and to provide a useful framework for ethical analysis in the health professions. However, those principles do not provide a full philosophical justification for decision making. In situations where there is conflict between principles, it may be necessary to choose between them or to assign greater weight to one. Practical problems in public health ethics require that these principles be made more applicable through a process of specification and reform ${ }^{11}$.

2. Case-based approach:

Sometimes, the specific decisions that emerge in particular cases may remain unaddressed by the principles. Such decisions are often made by focusing on the circumstances of the case at hand and the moral context in which the case rests. Case-based methods such as casuistry are grounded in analogical reasoning, appeal to paradigmatic cases, and practical judgment ${ }^{11,12}$. Here, decision making takes place at the level of the particulars of the case itself. Given a case and a particular decision to be made, maxims are identified that have bearing on the case.

Other approaches to moral reasoning, such as rights-based theories, duty-based theories, contractarianism, ethics of care, narrative ethics, and communitarianism have not been widely applied in public health ${ }^{5}$. 
Public Health Research: Ethical Concerns: A framework for public health ethics will help public health professionals recognize the multiple and varied moral issues in their work. Public health ethics must emphasize positive rights as well. Public health has affirmative obligations to improve the public's health, ensure 'health for all' and to reduce certain social inequities. Hence, a code of public health ethics is also needed to address such social justice. Some emerging issues related to ethical aspects of public health research are discussed below.

Ethical issues in public health surveillance:

Public health professionals have ethical obligations to both maximize the potential benefits of routinely collected surveillance and disease registry data and minimize risks and potential harms. Steps taken to assure the quality of data collected by public health surveillance systems and disease registries maximize the potential benefits of the data. Registry data must be accurate, complete, and timely ${ }^{5}$.

Minimizing risks and providing benefits:

Ethical concerns in epidemiology and public health practice often relate to the obligations of health professionals to acquire and apply scientific knowledge aimed at maintaining and restoring public health while respecting individual rights ${ }^{5}$. Potential societal benefits must often be balanced with risks and potential harms to individuals and communities, which is particularly important in epidemiologic studies of vulnerable populations e.g. children, prisoners, old people, and populations that are socioeconomically disadvantaged ${ }^{13}$.

Obligations to communities:

These obligations include communicating the results of public health/epidemiologic studies at the earliest possible time, after appropriate scientific peer review, so that the widest range of readers are able to get benefit from the information. Researchers should strive to carry out studies in a way that is scientifically valid and interpret and report the results of their studies in a way that is scientifically accurate and appropriate ${ }^{5}$. Moreover, they should respect cultural diversity in carrying out studies and in communicating with members of affected communities ${ }^{14}$.

Informed consent, privacy and confidentiality:

Informed consent provisions in public health studies ensure that research participants will make a free choice and also give institutions the legal authorization to proceed with the research $^{15}$. This includes the purpose of the research, the scientific procedures, anticipated risks and benefits, any inconveniences or discomfort, and the participant's right to refuse participation or to withdraw from the research at any time. Seeking and updating informed consent is fundamental to good practice in research involving human participants ${ }^{16}$. Special considerations for obtaining informed consent may arise in public health studies of socioeconomically deprived people. People who have limited access to health care may misunderstand an invitation to participate in a study as an opportunity to receive medical care. In addition, they may be reluctant to refuse participation when the researcher is viewed as someone in a position of authority, such as a physician or university professor. Socioeconomically deprived people may also be more motivated to participate in studies involving financial incentives for participation ${ }^{17}$. A further issue is that there is often a need to translate informed consent statements into a language other than English ${ }^{18}$. 
Another important way in which public health researchers reduce potential harms and risks to participants in research is by protecting the privacy of the participants and the confidentiality of their health information ${ }^{19}$. Specific measures taken by researchers to protect the confidentiality of health information include keeping records under lock and key, limiting access to confidential records, discarding personal identifiers from data collection forms and computer files whenever feasible, and training the staff about the importance of privacy and confidentiality protection ${ }^{20}$. Other measures that have been employed to safeguard health information include encrypting computer databases, limiting geographic detail, and suppressing cells in tabulated data where the number of cases in the cell is small ${ }^{21}$.

Avoiding and disclosing conflicts of interest:

Other ethical issues that arise in the professional practice of epidemiology relate to how to deal with potential conflicts of interest, in order to 'maintain public trust in epidemiology and sustain public support for health research ${ }^{22,23}$. Conflicts of interest can affect scientific judgment and harm scientific objectivity ${ }^{16}$. Studies have suggested that financial interests and researchers' commitment to a hypothesis can influence the reported research results $^{23,24}$. Hence, researchers should disclose financial interests and sources of funding when publishing research results. It may also be important to disclose information about potential or actual financial conflicts of interest when obtaining informed consent from research participants.

The Role Of The Institutional Ethical Review Committee (Erc): The purpose of research ethics committees or institutional ethical review committees (ERCs) is to ensure that studies involving human research participants are designed to conform the relevant ethical standards and that the rights and welfare of participants are protected ${ }^{25}$. Research ethics committees should not function under political control or one's sweet will ${ }^{26}$. Ethics committees must be independent of research organizations. This independence relates to their decisions, not their operating processes ${ }^{16}$. A methodical review by such committee ensures that studies have a "favorable balance of potential benefits and risks, and that the participants are selected equitably, and that procedures for obtaining informed consent are adequate" 27 . It is praise-worthy that National Institute of Preventive and Social Medicine (NIPSOM), all the government medical colleges and different specialized government health institutes have got their own ethical review committees (ERCs). Moreover, Bangladesh Medical Research Council (BMRC), the focal point for health research in the country, has got a strong 'National Research Ethics Committee' to review the ethical aspects of a research project ${ }^{28}$.

The first and foremost addressed issues are informed consent, privacy and confidentiality of data, risk-benefit ratio of the community/participants ${ }^{29}$. Other issues concerned in the guidelines include those pertaining to scientific misconduct, intellectual property and data sharing, publication of research findings, and cross-cultural or international health research ${ }^{30}$. However, any research now requires only a single ethical review, irrespective of the authority concerned (but preferably done by the parent institution) and number of sites involved. What is needed in our country is that all research ethics committees in 
Bangladesh should operate in a standard fashion, providing an impartial, unbiased review and quick decision. Directorate General of Health Services (DGHS), Bangladesh has already published a 'National Health Research Strategy' with technical assistance from Bangladesh Medical Research Council (BMRC) and World Health Organization (WHO) featuring different aspects of biomedical research which include institutional framework, priority setting, ethical clearance, financing, monitoring and evaluation, capacity development, dissemination and utilization of research results ${ }^{31}$.

Conclusion: Bioethics, as a discipline, helps health care professionals identify and respond to moral dilemmas in their work. Public health is what we, as a society, do collectively to assure the conditions for people to be healthy ${ }^{1}$. Hence, a framework of ethics analysis geared specifically for public health is needed, both to provide practical guidance for public health professionals and to highlight "the defining values of public health, values that differ in morally relevant ways from values that define clinical practice and research" 8 . Besides, conflict of interest of the researchers, indemnity for the protection of participants, and confidentiality of data are widely accepted as core ethical issues in any research. Therefore, we should look into these matters seriously in the field of public health research. Of course, public policy is based on many factors in addition to public health goals and ethical reasoning, but it should not lead to the politically preferable option for a given time.

\section{References:}

1. Beaglehole R, Bonita R. Public health at the crossroads: achievements and prospects. $2^{\text {nd }}$ ed. Cambridge: Cambridge University Press; 2004.

2. Institute of Medicine. Committee for the study of the future of public health. The future of public health. Washington, DC: National Academy Press; 1988.

3. Callahan D, Jennings B. Ethics and public health: forging a strong relationship. Am J Public Health 2002; 92: 169-76.

4. Kass NE. Public health ethics: from foundations and frameworks to justice and global public health. J Law Med Ethics 2004; 32: 232-42.

5. Coughlin SS. Ethical issues in epidemiologic research and public health practice. Emerging Themes in Epidemiology 2006, 3: 16-.

6. Coughlin SS, Beauchamp TL, Weed DL. Historical foundations. In: Ethics and epidemiology. $2^{\text {nd }}$ ed. New York: Oxford University Press; 2009.

7. Sen A. Why health equality. In: Anand S, Peter F, Sen A. editors. Public health, ethics, and equity. $1^{\text {st }}$ ed. New York: Oxford University Press; 2004.

8. Kass NE. An ethics framework for public health. Am J Public Health 2001; 91(11): 1776-82.

9. Gostin LO. editor. Public health law and ethics: a reader. $1^{\text {st }}$ ed. Berkeley: University of California Press; 2002. 
10. Beauchamp TL, Childress JF. Principles of biomedical ethics. $5^{\text {th }}$ ed. New York: Oxford University Press; 2001.

11. Beauchamp TL. Moral foundations. In: Coughlin SS, Beauchamp TL, Weed DL. eds. Ethics and epidemiology. $2^{\text {nd }}$ ed. New York: Oxford University Press; 2009.

12. Coughlin SS, Soskolne CL, Goodman KW. Case analysis and moral reasoning. In: Coughlin SS. editor. Case studies in public health ethics. $2^{\text {nd }}$ ed. Washington, DC: American Public Health Association; 2009.

13. Coughlin SS. Ethically optimized study designs in epidemiology. In: Coughlin SS, Beauchamp TL, Weed DL. editors. Ethics and epidemiology. $2^{\text {nd }}$ ed. New York: Oxford University Press; 2009.

14. Public Health Leadership Society. Principles of the ethical practice of public health. Version 2.2. 2002.

15. Shulz M. Legal and ethical considerations in securing consent to epidemiologic research in the United States. In: Coughlin SS, Beauchamp TL, Weed DL. editors. Ethics and epidemiology. $2^{\text {nd }}$ ed. New York: Oxford University Press; 2009.

16. Pattison J, Stacey T. Research bureaucracy in the United Kingdom: seeking a balance: response from the Department of Health and COREC. BMJ 2004; 329(7466): 622.

17. Smith NL. The context of investigations in cross-cultural evaluations. Studies in Educational Evaluation 1991; 17: 3-21.

18. Macklin R. Against relativism: cultural diversity and the search for ethical universals in medicine. $1^{\text {st }}$ ed. New York: Oxford University Press; 1999.

19. Parmet WE. Populations, public health, and the law. $1^{\text {st }}$ ed. Washington, DC: Georgetown University Press; 2009.

20. Coughlin SS. Ethically optimized study designs in epidemiology. In: Coughlin SS, Beauchamp TL, Weed DL. editors. Ethics and epidemiology. $2^{\text {nd }}$ ed. New York: Oxford University Press; 2009.

21. Wynia MK, Coughlin SS, Alpert S, Cummins DS, Emanuel LL. Shared expectations for protection of identifiable health care information: report of a national consensus process. J Gen Intern Med 2001; 16(2): 100-11.

22. Centers for Disease Control and Prevention (CDC). Framework for program evaluation in public health. MMWR 1999; 48(RR11): 1-40.

23. Seigel D. Clinical trials, epidemiology, and public confidence. Stat Med 2003; 22: 3419-25.

24. Jamrozik K. Research ethics paperwork: what is the plot we seem to have lost? BMJ 2004; 329: 286-7.

25. Fairchild AL, Bayer R. Ethics and the conduct of public health surveillance. Science 2004; 303: 631-2.

26. Wald SD. Bureaucracy of ethics applications. BMJ 2002; 329: 282-4.

27. Jones AM, Bamford B. The other face of research governance. BMJ 2004; 329:280-1.

28. Bangladesh Medical Research Council (BMRC). RICH. 2008; : . 
29. Council for International Organizations of Medical Sciences. International guidelines for ethical review of epidemiological studies. Law Med Health Care 1991; 19: 247-58.

30. Beauchamp TL, Cook RR, Fayerweather WE, Raabe GK, Thar WE, Cowles SR, et al. Ethical guidelines for epidemiologists. J Clin Epidemiol 1991; 44(Suppl.1): 151-69.

31. Directorate General of Health Services (DGHS). National Health Research Strategy. Ministry of Health and Family Welfare, Government of the People's Republic of Bangladesh, 2009. 